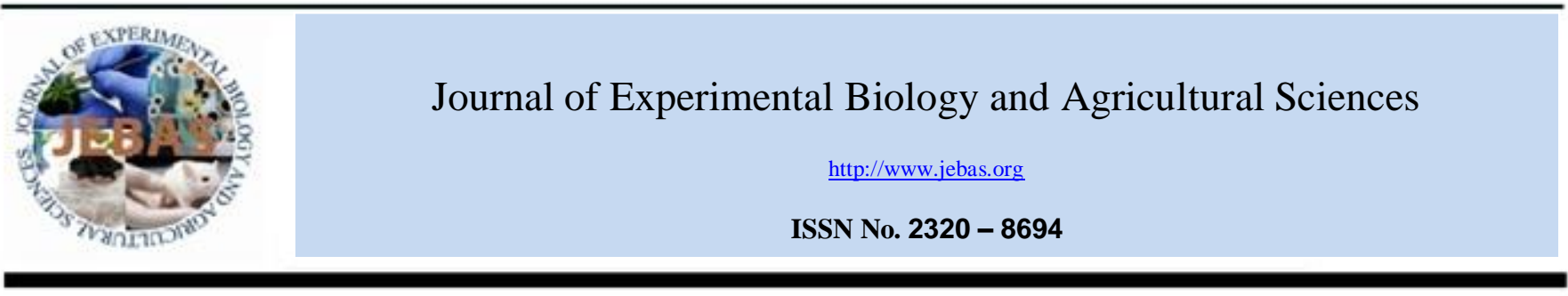

\title{
IMPACT OF HYBRIDIZATION ON THE PATTERN OF MOLECULAR GENETIC VARIATION IN MAIZE (Zea mays)
}

\section{Ayoob O Mohammed}

College of Agriculture, University of Anbar- Abu Ghraib- Baghdad/ IRAQ

Received - September 24, 2015; Revision - October 05, 2015; Accepted - November 08, 2015

Available Online - December 10, 2015

DOI: http://dx.doi.org/10.18006/2015.3(6).479.486

\author{
KEYWORDS \\ Maize \\ Hybridization \\ Genetic Polymorphism \\ RAPD marker
}

\begin{abstract}
Present study was conducted to analyze the impact of hybridization on the molecular variation of maize. Total ten RAPD markers were used to assess the genetic diversity in hybridized maize crop and its relationships with their respective F1 hybrids was also established in present study. Among these, five were succeeding to amplify DNA fragments through PCR technique and produced total 31 fragments. Out of these thirty one, twenty two showed polymorphism and mean of these polymorphic percent scored $64.5 \%$. Least genetic similarity was reported in L2×T1 against other genotypes; on the other hand L2×T2 and L3×T1 became closely related genera and gained 100 percent genetic similarity. Generally, the F1 hybrids acted in a different way compared with their corresponded parental lines, and the latest tend to occupy separate cluster in Dendrogram tree as they generally gained low values of genetic similarity. Meanwhile F1 hybrids showed high level genetic similarity among themselves. Result of present study revealed a clear impact of hybridization on the genetic diversity among maize genotypes and could play an important role in developing new genotypes.
\end{abstract}

* Corresponding author

E-mail: dr.job77@gmail.com (Ayoob O Mohammed)

Peer review under responsibility of Journal of Experimental Biology and Agricultural Sciences.

Production and Hosting by Horizon Publisher (http://publisher.jebas.org/index.html).

All rights reserved.
All the article published by Journal of Experimental Biology and Agricultural Sciences is licensed under a Creative Commons Attribution-NonCommercial 4.0 International License Based on a work at www.jebas.org.

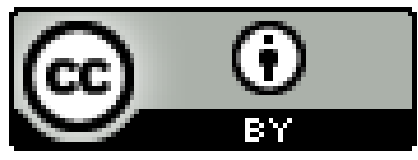




\section{Introduction}

Still we haven't understand many phenomena surrounding to us, hybrid vigor that feed millions of people are one of the phenomena that still undergo mystery until the moments even at the molecular level. Researchers are still working on making a better understanding on the mechanism of heterosis action and tracking the genetic heterogeneity from parents during its transition which in turn affect the performance of hybrids (Alfalahi et al., 2012).

Many of the previous studies addressed the supposed influence of genetic divergence between the parents on the strength of the hybrids, but most of those studies relied on superficial indicators to judge the presence or absence of genetic heterogeneity. It is well known that the morphology of the plant is largely affected by environmental fluctuations, which is reflected on the accuracy of the collected data (Bardakci, 2001; Gratani, 2014). The scientific scene witnessed the using of new molecular biology techniques and large numbers of highly informative DNA markers in order to develop some distinguishing differences between genetic variants regardless of the environmental impacts. Accordingly, from last few years random amplified polymorphic DNA (RAPD) technique became most commonly used molecular markers in evaluating molecular variations even within the same species.

According to Liet \& Thinh (2009) RAPD marker is an attractive method for the analysis of genetic diversity among maize accessions and they detected that level of polymorphism reached $61.8 \%$ in local waxy maize accessions and $88.3 \%$ in local normal maize accessions by hybridization. Similarity values and polymorphic index allowed authors to distinguish 18 groups of maize accessions with distinctive genetic profiles. The molecular data grouped the waxy maize accessions into 11 main clusters and normal maize into 7 groups. Furthermore, Leal et al. (2010) examined the efficiency of RAPD and SSR markers in discriminating among popcorn genotypes. The nine used RAPD primers yielded 126 bands, of which 104 (82.53\%) were polymorphic and the recording polymorphisms average of $11.6 \%$ per primer. Authors concluded that both RAPD and SSR primers were efficient in evaluating genetic diversity in the evaluated genotypes, though RAPDs yielded more polymorphisms. Similarly, high level polymorphism (73.02\%) was also reported by Mukharib et al. (2010), when they used RAPD marker to assess genetic diversity in a selected group of maize inbred lines. The maximum genetic distance was $29.7 \%$, while the minimum observed genetic distance was $12.8 \%$. Based on these results, authors believed that the RAPD markers can be successfully employed in identifying genetic diversity in maize inbred lines.

Shah et al. (2010) were grouped maize into four main groups. Among these some clusters contain single and some contain multiple genotypes and the genetic similarities ranged from 60 to $100 \%$. Similarly, Yadav \& Singh (2010) conducted a study with the aim of assessing the role of RAPD molecular marker in establishing relationships among maize genotypes. According to these researchers all the inbred lines can be confirmed on the basis of morphologically and physiologically traits with the help of RAPD. The genetic distance varying from 42 to $65 \%$, and close genetic relationship was detected among the used genotypes which turn resulted in close clusters formation.

Alfalahi et al. (2012) used RAPD markers to evaluate trends in genetic diversity among twenty $\mathrm{cms}$ line populations derived from early and advanced selection cycles. All the 10 RAPD primers used for initial screening were found polymorphic. As author mentioned, the genetic similarity was ranged from 50 to $94 \%$. Based on the bivariate (1-0) data and genetic similarity with the use of UPGMA cluster method, the dendrogram separated the studied populations into five major clusters.

Mrutu (2015) also tried to assess the seed genetic purity of forty seven hybrid maize using random amplified polymorphic DNA markers and reported total 134 polymorphic bands which shows genetic similarity ranged from 0.09 to 0.99 . Cluster analysis based on Jaccard's similarity coefficient grouped the genotypes into two major clusters; one cluster contained 42 genotypes and the other cluster contained five genotypes. Result of study concludes that the identical phenotypes were found to be genetically different, and with aid of RAPD markers 94 of these were found polymorphic and scoring 83.9 percent of polymorphism. Results of study revealed that only some pairs displayed genetic divergence and this may due to common ancestral parent (Hemavathy, 2015).

Further to all of the above, this study may be an addition to the previous efforts which have been made to assess the genetic diversity and relationships among maize germplasm collections using DNA markers. Moreover, an effort has been made to track genetic variation at the molecular level from parents to their F1 hybrids and impact of hybridization on the stability of the genetic relationship was also assessed by using phylogenetic analysis.

\section{Materials and Methods}

\subsection{DNA Extraction}

Total genomic DNA was extracted from maize seeds by using Genomic DNA Mini Kit-Plant (Geneaid Biotech Ltd.-Taiwan) and extraction was carried out by following instruction mentioned in the manufacture protocol.

2.2 Estimation of the quality and quantity of the isolated genomic DNA

The quality of total extracted genomic DNA was assessed by mixing $7 \mu \mathrm{l}$ of each DNA sample with $3 \mu \mathrm{l}$ of loading dye (0.25g Bromphenol blue dye; $30 \mathrm{ml}$ glycerol). 
Table 1 Primers used for random amplification of maize genotypes.

\begin{tabular}{|c|c|c|c|}
\hline RAPD primers & Sequence & RAPD primers & Sequence \\
\hline$O P A-07$ & 5'-AAGTCCGCTC -3' & $O P D-20$ & $5^{\prime}$-TGTCATCCCC -3' \\
\hline OPA-09 & 5'-GGGTAACGCC -3' & OPI-01 & 5'-AACCTGGCA-3' \\
\hline$O P A-11$ & 5'-CAATCGCCGT -3' & OPO-04 & 5'-AACCTGGCA-3' \\
\hline$O P A-13$ & $5^{\prime}$-CAGCACCCAC -3' & $O P N-16$ & $5^{\prime}$-CAAGGTGGGT -3' \\
\hline$O P C-12$ & $5^{\prime}$-TGTCATCCCC -3' & $G B-08$ & $5^{\prime}$-GTCCACACGG -3' \\
\hline
\end{tabular}

This was followed by the running this mixed samples on $0.8 \%$ agarose gel submerged in $1 \times \mathrm{TBE}$ (Tris base, Boric acid, EDTA) buffer. After 30 minutes gel was stained for 20 minutes with ethidium bromide in a dark place and visualized and photographed under UV light using White Film Camera (667).

DNA was quantified by checking the optical density (OD) at 260 and $280 \mathrm{~nm}$ wave length. The purity of genomic DNA was determined by the A260/A280 absorbance ratio. According to the quantity of extracted DNA, samples were diluted to prepared final concentration of 50ng/ $\mu$ l. DNA concentration was estimated through the following formula:

DNA concentration $(\mu \mathrm{g} / \mathrm{ml})=$ O.D. $260 \mathrm{~nm} \times 40 \times$ Dilution factor

Ten RAPD primers of different series (GB, A, C, D and N) were obtained from Geneaid Biotech. Ltd., Taiwan in lypholized form, and used for the polymorphism study (Table1). Primers were dissolved in sterile distilled deionized water to make the final concentration of $(10 \mathrm{pmol} / \mu \mathrm{l})$ as par manufactured instruction.

Amplification reactions were carried out in $20 \mu \mathrm{l}$ volume (5 $\mu \mathrm{l}$ DNA, $2 \mu \mathrm{l}$ of primer, $1.5 \mu \mathrm{lNaCl}, 6.5 \mu \mathrm{l}$ of d.d. water added to $5 \mu \mathrm{l}$ of ready master mix), Labnet thermal cycler (USA) was used to amplify PCR products with the recommended PCR thermoprofile viz. Initial denaturation was performed at $94^{\circ} \mathrm{C}$ for $5 \mathrm{~min}$., 45 cycles of denaturation was followed at $94^{\circ} \mathrm{C}$ for $1 \mathrm{~min}$., then primer annealing was done at $36^{\circ} \mathrm{C}$ for $1 \mathrm{~min}$., finally extension step was for $2 \mathrm{~min}$. at $72^{\circ} \mathrm{C}$.

After amplification, $7 \mu \mathrm{l}$ from each sample was mixed with 3 $\mu \mathrm{l}$ of loading dye $(0.25 \mathrm{~g}$ Bromphenol blue dye; $30 \mathrm{ml}$ glycerol) and run on $1.5 \%$ agarose gel submerged in $1 \times \mathrm{TBE}$ (Tris base, Boric acid, EDTA) buffer, after 1 hour gel was stained with ethidium bromide in a dark place for 20 minutes. The gel was visualized and photographed under UV light using White Film Camera (667).

Genetic similarity was analyzed with aid of Popgene computer software (version 32). Every scorable band was considered as single allele/locus and scored 1 for the presence of band and 0 for the absence $(0)$. Genetic similarity was calculated by using Unweighted Pair Group of Arithmetic Means (UPGMA) procedures as described by Nei \& Li (1979).

Genetic Similarity $(\mathrm{GS})=2 \mathrm{Nij} /(\mathrm{Ni}+\mathrm{Nj})$

Where: Gs=Genetic Similarity between two populations; $\mathrm{Nij}=$ Total number of loci (bands) in populations $\mathrm{i}$ and $\mathrm{j} ; \mathrm{Ni}=$ Total number of loci (bands) in population $\mathrm{i} ; \mathrm{Nj}=$ Total number of loci (bands) in population $\mathrm{j}$.

While the polymorphism was estimated according to the following formula (Alfalahi et al., 2012):

Polymorphism \% $=(\mathrm{Np} / \mathrm{Nt}) \times 100$

Where: $\mathrm{Np}=$ the number of polymorphic bands of primer; $\mathrm{Nt}=$ the total number of bands of same primer.

\section{Results and Discussion}

3.1 Polymorphisms among the selected maize genotypes

All the used primers resulted in successful amplifications were polymorphic; hence, they proved to be very useful in resolving the genetic structure of the studied genotypes. The number of amplified fragments varied from 4 to 10 fragments with molecular size mean ranged from $141.2 \mathrm{bp}$ to $321.6 \mathrm{bp}$ (Table 2 ). The highest number of polymorphic fragments (8) was produced by the primer OPN-16, while the maximum percent of polymorphism (87.5\%) was recorded with the primer OPC12. These findings were agreed with the polymorphism detected by Leal et al. (2010). Primers efficiency between the used genotypes was varied from primer to primer and it depending on its ability to amplified unique fragment which could be used as finger print for related genotype. The percentages of polymorphism were ranged from 25 to $87.5 \%$ recording a mean of $64.4 \%$. Similar type of findings was reported by Yadav \& Singh (2010) and Mukharib et al. (2010). Some genotypes has specific fragment or band on the gel and these are the unique locus for that genotype, like fragment with molecular size of $200 \mathrm{bp}$ which have been missed in L1, L2, $\mathrm{T} 2$ and $\mathrm{T} 3$ with the using of GB-08 primer (Figure 1). 
The F1 hybrid L1×T3 gained a new annealing site with OPC12 primer resulted in producing unique fragment with molecular size of $220 \mathrm{bp}$, meanwhile the same hybrid lost two annealing sites should produce fragments with molecular size ranged from 250 to $290 \mathrm{bp}$ (Figure 1).

\subsection{Phylogenetic Analysis}

It was expected that each F1 hybrids will be genetically closest relative to both of his parents or at least one of them. It was expected because the genetic material of an individual is a combination of his parent's genetic materials and similar type of opinion also created for phenotypic characters. This general rule is not application without any exceptions, factors which are responsible for affecting this rules mutations, crossing over, transposable elements, in addition to the epigenetic effects like DNA methylation which may alters the individual performance without going through DNA sequence changes.

Genetic distance is a parameter which providing important insight into the differentiation pattern among genotypes. In present study it was persisted to separate the analysis of genetic relatedness of parents among F1 hybrids, and then joint them together in one scheme in attempt to detect the impact of hybridization on the genetic relationships over generations.

Analysis of phylogram tree (Dendrogram) it can be observed that there is a clear impact of hybridization on the genetic divergence among the used genotypes (Fig. 2, 3 and 4). Here it was also reported that the F1 hybrids acted differently compared with their corresponded parental lines. Also, the parental lines occupied separate part in dendogram tree which represented low values of genetic similarity while many of F1 hybrids genetically comes closed to each other which represented higher values of genetic similarity.

Maximal genetic similarity among the tested genotypes was $92 \%$ and it was reported between the genotype $\mathrm{T} 1$ and $\mathrm{T} 2$ (Table 3) while the minimal genetic similarities was recorded between the selected genotype L1 and L4 (70\%). Results presented in table revealed that lines were genetically divergent more than testers which may be because of its genetic background. When this line compared against testers, it was reported that L1 and T2 showed the highest genetic similarity and it reached up to $91.9 \%$. On the other hand, the minimal value of genetic similarity was $71.4 \%$ and $71.8 \%$ between $\mathrm{L} 3$ line and each of $\mathrm{T} 1$ and $\mathrm{T} 2$ testers respectively.

Table 2 Amplified and polymorphic DNA fragments generated by RAPD primers and percentage of polymorphism in selected maize genotypes.

\begin{tabular}{|llllll|}
\hline $\begin{array}{c}\text { RAPD } \\
\text { primers }\end{array}$ & $\begin{array}{c}\text { Total number of } \\
\text { fragments }\end{array}$ & $\begin{array}{c}\text { No. of polymorphic } \\
\text { fragments }\end{array}$ & \multicolumn{2}{c|}{$\begin{array}{c}\text { Percent of polymorphism } \\
(\%)\end{array}$} & $\begin{array}{c}\text { Size of fragments } \\
\text { (bp) }\end{array}$ \\
\hline GB-08 & 4 & 1 & 25 & $172-320$ \\
\hline OPA-09 & 4 & 2 & 50 & $130-340$ \\
\hline OPC-12 & 8 & 7 & 87.5 & $110-612$ \\
\hline OPD-20 & 5 & 4 & 80 & $140-620$ \\
\hline OPN-16 & 10 & 8 & 80 & $154-310$ \\
\hline Total & $\mathbf{3 1}$ & $\mathbf{2 2}$ & $\mathbf{6 4 . 5}$ & $\mathbf{1 4 1 . 2}-\mathbf{4 4 0 . 4}$ \\
\hline
\end{tabular}

Table 3 Genetic similarity values of seven parental maize lines with the used of five RAPD primers (OPA-09, OPC-12, OPD-20, OPN16 and GB-08).

\begin{tabular}{|lccccccc|}
\hline Genotypes & L1 & L2 & L3 & L4 & T1 & T2 & T3 \\
\hline L1 & 1.000 & & & & & & \\
\hline L2 & 0.919 & 1.000 & & & & & \\
\hline L3 & 0.789 & 0.821 & 1.000 & & & & \\
\hline L4 & 0.700 & 0.780 & 0.905 & 1.000 & & & \\
\hline T1 & 0.850 & 0.829 & 0.714 & 0.773 & 1.000 & & \\
\hline T2 & 0.919 & 0.895 & 0.718 & 0.732 & 0.927 & 1.000 & \\
\hline T3 & 0.757 & 0.789 & 0.872 & 0.878 & 0.780 & 0.842 & 1.000 \\
\hline
\end{tabular}

Here L1, L2, L3, L4 lines and T1,T2 and T3 testers with their respective top cross hybrids. 

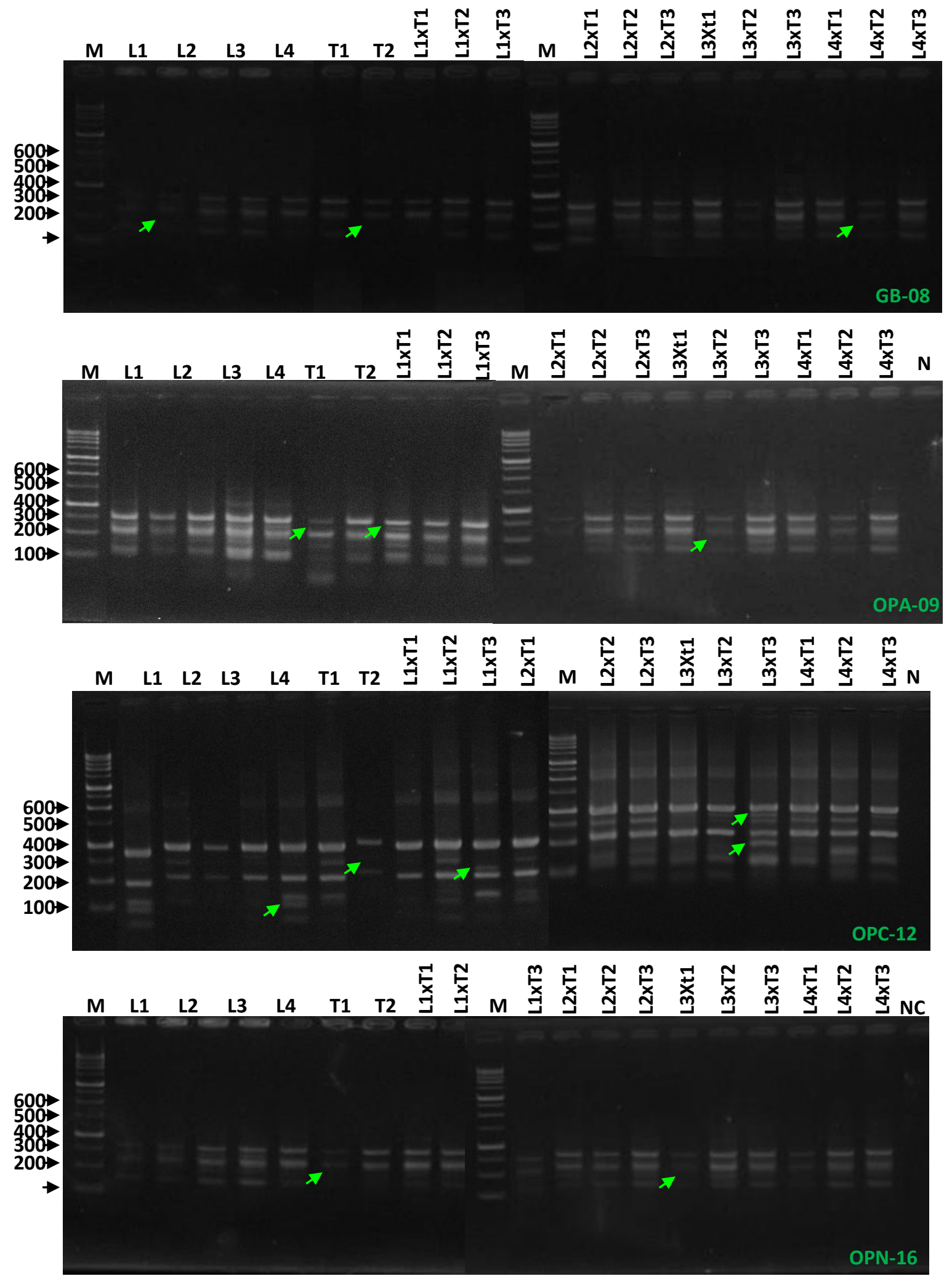

Figure 1 PCR Amplified products of 19 maize genotypes using four RAPD primers (GB-08 (1), OPA-9 (2), OPC-12 (3) and OPN-16(4) running on agaros gel (L1, L2, L3, L4 lines and T1,T2 and T3 testers with their respective top cross hybrids). 


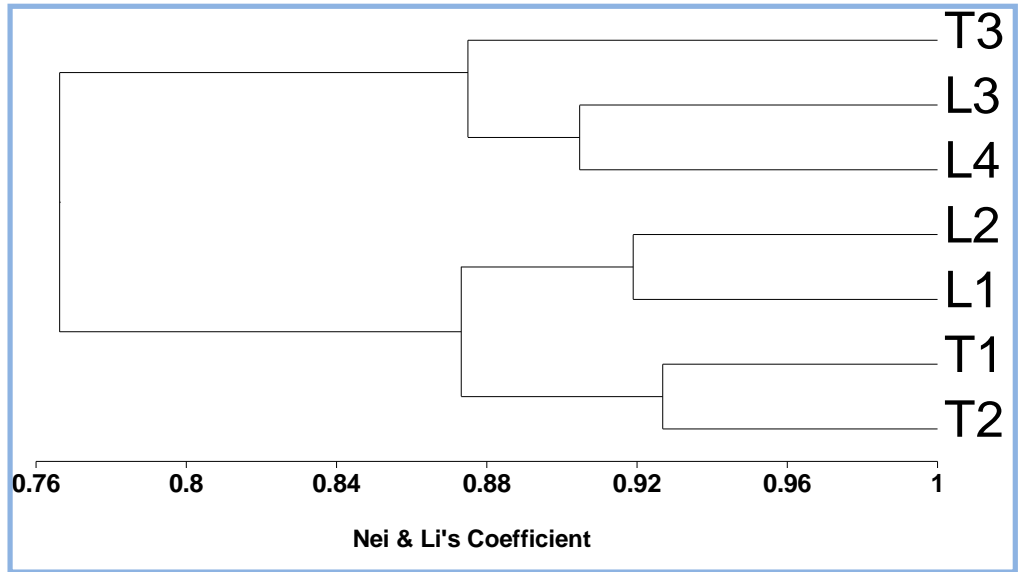

Figure 2 Constructed dendrogam of seven parental maize lines based on genetic similarity values with aid of five RAPD markers (OPA09, OPC-12, OPD-20, OPN-16 and GB-08).

These results confirmed by the cluster analysis which separate parental genotypes into two main clusters I and II (Figure 2). The first cluster composed of two lines (L3 and L4) and one tester (T3). Whereas, the second cluster was composed of two sub-cluster, the first composed of $\mathrm{T} 1$ and $\mathrm{T} 2$ testers, while the second was composed of L1and L2 lines.

In order to study the effect of hybridization process on the genetic relationship among genotypes pedigree, F1 hybrids which results from LinexTester crossing system were genetically analyzed with aid of RAPD molecular markers. The values of GS among F1 hybrids (Table 4) showed clearly that hybridization played different role in the different genotypes. For example, surprisingly L $2 \times \mathrm{T} 2$ and $\mathrm{L} 3 \times \mathrm{T} 1$ were matched completely scoring $100 \%$ genetic similarity even they are not sharing the same parents, but in the same time $\mathrm{T} 1$ and T2 testers gained the highest GS value among parental genotypes this may explain the identical performance of their hybrids.
The high GS value between L4×T1 and L4×T3 hybrids was expected as they have L4 line participate in both of them, on the opposite direction $\mathrm{L} 1 \times \mathrm{T} 3$ hybrid choose to act differently with the lowest GS values $(\approx 73 \%)$ and occupied one cluster alone.

Figure 4 is showing a combined dendrogram of all the tested genotypes altogether (Lines, Testers and F1 hybrids) in one (Fig. 4). F1 hybrids are genetically closet to their ancestor parents as expected, but this is not happened every time and some hybrids separate from their parents and constrain a new genetic relationship with different genotypes like L1×T2 which its DNA sequence related with the used primers become more identical with that of $\mathrm{T} 1$ tester scoring GS similarity reached 93.3\%. The L2 line was succeeded in conservation of its family genetic relationship as it sustain the closet to its F1 hybrid L2×T3 with GS value of $95 \%$ (Table5).

Table 4 Genetic similarity values of 12 F1 maize hybrid with the used of five RAPD primers (OPA-09, OPC-12, OPD-20, OPN-16 and GB-08).

\begin{tabular}{|c|c|c|c|c|c|c|c|c|c|c|c|c|}
\hline Genotypes & L1XT1 & L1XT2 & L1XT3 & L2XT1 & L2XT2 & L2XT3 & L3XT1 & L3XT2 & L3XT3 & L4XT1 & L4XT2 & L4XT3 \\
\hline L1XT1 & 1.000 & & & & & & & & & & & \\
\hline L1XT2 & 0.810 & 1.000 & & & & & & & & & & \\
\hline L1XT3 & 0.800 & 0.818 & 1.000 & & & & & & & & & \\
\hline L2XT1 & 0.773 & 0.833 & 0.783 & 1.000 & & & & & & & & \\
\hline L2XT2 & 0.821 & 0.744 & 0.732 & 0.756 & 1.000 & & & & & & & \\
\hline L2XT3 & 0.850 & 0.818 & 0.810 & 0.783 & 0.927 & 1.000 & & & & & & \\
\hline L3XT1 & 0.821 & 0.744 & 0.732 & 0.756 & 1.000 & 0.927 & 1.000 & & & & & \\
\hline L3XT2 & 0.800 & 0.864 & 0.810 & 0.826 & 0.829 & 0.905 & 0.829 & 1.000 & & & & \\
\hline L3XT3 & 0.826 & 0.920 & 0.792 & 0.885 & 0.851 & 0.875 & 0.851 & 0.875 & 1.000 & & & \\
\hline L4XT1 & 0.878 & 0.800 & 0.791 & 0.809 & 0.952 & 0.930 & 0.952 & 0.884 & 0.898 & 1.000 & & \\
\hline L4XT2 & 0.829 & 0.844 & 0.884 & 0.851 & 0.857 & 0.930 & 0.857 & 0.930 & 0.857 & 0.909 & 1.000 & \\
\hline L4XT3 & 0.884 & 0.851 & 0.800 & 0.857 & 0.909 & 0.933 & 0.909 & 0.889 & 0.941 & 0.957 & 0.913 & 1.000 \\
\hline
\end{tabular}




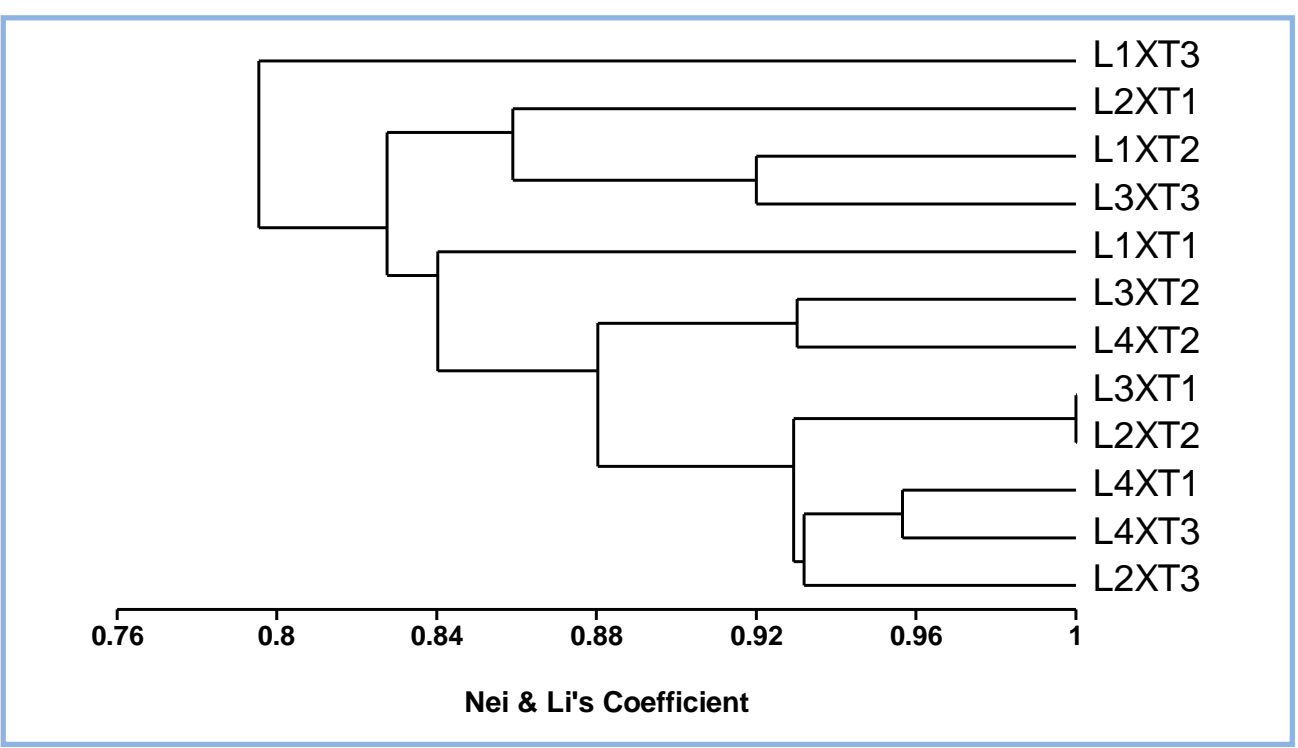

Figure 3 Dendrogam of 12F1 maize hybrids based on genetic similarity values with aid of five RAPD markers (OPA-09, OPC-12, OPD20, OPN-16 and GB-08).

It's clear that small group of genotypes occupied one subcluster consist of L3, L4, T3 and L1×T1 hybrid, while the rest of genotypes were occupied the other sub-cluster, except L1×T3and L2×T1hybrids which acts differently against each other and the rest of genotypes as they split up lonely. These findings are in accordance with the findings of Shah et al. (2010), which revealed that clusters showed a range containing from a single to multiple genotypes in a cluster, based on genetic similarities started with $60 \%$ and ended with $100 \%$. The results showed firmly that the genetic relationship could shift totally and new genetic relationship could be settled for many reasons such as crossing over process and Ac/Ds transposable elements. There is a need to use large number of RAPD DNA markers or SSR for more accuracy and get unbiased estimation for the role of hybridization in creating new genetic materials.

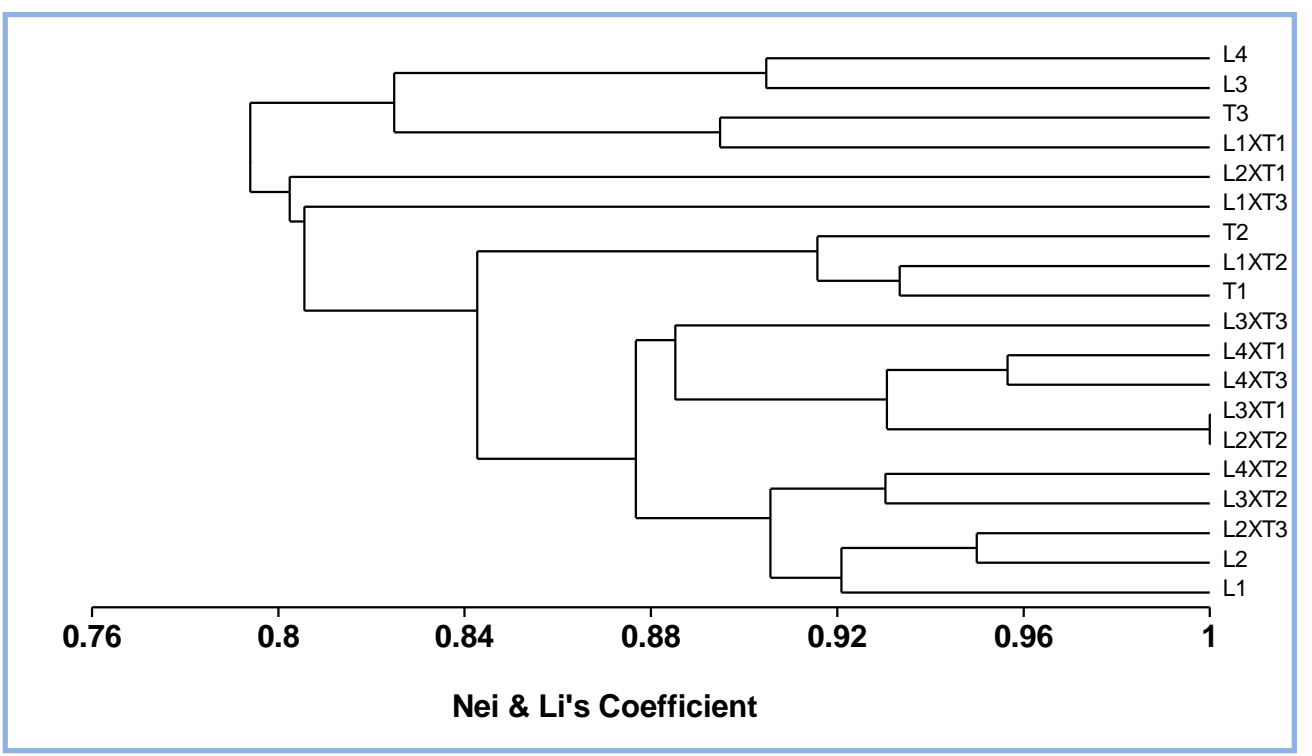

Figure 4 Constructed dendrogam of ninteen maize genotypes based on genetic similarity values with aid of five RAPD markers (OPA09, OPC-12, OPD-20, OPN-16 and GB-08). 


\begin{tabular}{|c|c|c|c|c|c|c|c|c|c|c|c|c|c|c|c|c|c|c|c|}
\hline \multicolumn{19}{|c|}{486} & Ayoob \\
\hline Genotypes & L1 & L2 & L3 & L4 & T1 & T2 & T3 & L1XT1 & L1XT2 & L1XT3 & L2XT1 & L2XT2 & L2XT3 & L3XT1 & L3XT2 & L3XT3 & L4XT1 & L4XT2 & L4XT3 \\
\hline L1 & 1.000 & & & & & & & & & & & & & & & & & & \\
\hline L2 & 0.919 & 1.000 & & & & & & & & & & & & & & & & & \\
\hline L3 & 0.789 & 0.821 & 1.000 & & & & & & & & & & & & & & & & \\
\hline L4 & 0.700 & 0.780 & 0.905 & 1.000 & & & & & & & & & & & & & & & \\
\hline T1 & 0.850 & 0.829 & 0.714 & 0.773 & 1.000 & & & & & & & & & & & & & & \\
\hline T2 & 0.919 & 0.895 & 0.718 & 0.732 & 0.927 & 1.000 & & & & & & & & & & & & & \\
\hline T3 & 0.757 & 0.789 & 0.872 & 0.878 & 0.780 & 0.842 & 1.000 & & & & & & & & & & & & \\
\hline L1XT1 & 0.811 & 0.842 & 0.769 & 0.780 & 0.829 & 0.895 & 0.895 & 1.000 & & & & & & & & & & & \\
\hline L1XT2 & 0.829 & 0.810 & 0.698 & 0.756 & 0.933 & 0.905 & 0.810 & 0.810 & 1.000 & & & & & & & & & & \\
\hline L1XT3 & 0.769 & 0.850 & 0.683 & 0.698 & 0.837 & 0.850 & 0.750 & 0.800 & 0.818 & 1.000 & & & & & & & & & \\
\hline L2XT1 & 0.744 & 0.773 & 0.711 & 0.766 & 0.809 & 0.773 & 0.727 & 0.773 & 0.833 & 0.783 & 1.000 & & & & & & & & \\
\hline L2XT2 & 0.895 & 0.872 & 0.850 & 0.762 & 0.762 & 0.821 & 0.769 & 0.821 & 0.744 & 0.732 & 0.756 & 1.000 & & & & & & & \\
\hline L2XT3 & 0.923 & 0.950 & 0.829 & 0.791 & 0.837 & 0.900 & 0.800 & 0.850 & 0.818 & 0.810 & 0.783 & 0.927 & 1.000 & & & & & & \\
\hline L3XT1 & 0.895 & 0.872 & 0.850 & 0.762 & 0.762 & 0.821 & 0.769 & 0.821 & 0.744 & 0.732 & 0.756 & 1.000 & 0.927 & 1.000 & & & & & \\
\hline L3XT2 & 0.872 & 0.900 & 0.732 & 0.837 & 0.884 & 0.900 & 0.750 & 0.800 & 0.864 & 0.810 & 0.826 & 0.829 & 0.905 & 0.829 & 1.000 & & & & \\
\hline L3XT3 & 0.800 & 0.826 & 0.809 & 0.857 & 0.857 & 0.826 & 0.826 & 0.826 & 0.920 & 0.792 & 0.885 & 0.851 & 0.875 & 0.851 & 0.875 & 1.000 & & & \\
\hline L4XT1 & 0.850 & 0.878 & 0.810 & 0.818 & 0.818 & 0.878 & 0.829 & 0.878 & 0.800 & 0.791 & 0.809 & 0.952 & 0.930 & 0.952 & 0.884 & 0.898 & 1.000 & & \\
\hline L4XT2 & 0.900 & 0.927 & 0.762 & 0.773 & 0.864 & 0.927 & 0.780 & 0.829 & 0.844 & 0.884 & 0.851 & 0.857 & 0.930 & 0.857 & 0.930 & 0.857 & 0.909 & 1.000 & \\
\hline L4XT3 & 0.857 & 0.884 & 0.864 & 0.870 & 0.826 & 0.884 & 0.884 & 0.884 & 0.851 & 0.800 & 0.857 & 0.909 & 0.933 & 0.909 & 0.889 & 0.941 & 0.957 & 0.913 & 1.000 \\
\hline
\end{tabular}

Table 5 Genetic similarity between the nineteen maize genotypes with the used of five RAPD primers (OPA-09, OPC-12, OPD-20, OPN-16 and GB-08).

\section{Conflict of interest}

Authors would hereby like to declare that there is no conflict of interests that could possibly arise.

\section{References}

Alfalahi AO, Elsahookie MM, Alobaidi BS (2012) Molecular variations of Maize CMS populations and subpopulations. Iraqi Journal of Biotechnology 11:292 -312.

Bardakci F (2001) Random amplified polymorphic DNA (RAPD) markers. Turkish Journal of Biology 25: 185-196.

Gratani L (2014) Plant phenotypic plasticity in response to environmental factors. Advances in Botany ID 208747, 17 pages. http://dx.doi.org/10.1155/2014/208747

Hemavathy AT (2015) Molecular marker based genetic diversity in quality protein maize. International Journal of Recent Scientific Research 6:3848-3851.

Leal AA, Mangolin CA, do Amaral AT Jr, Gonçalves LS, Scapim CA, Mott AS, Eloi IB, Cordovés V, da Silva MF (2010) Efficiency of RAPD versus SSR markers for determining genetic diversity among popcorn line. Genetics and Molecular Research 9 : 9-18. doi: 10.4238/vol9-1 gmr692.

Liet VV, Thinh PD (2009) Genetic diversity of local maize (Zea mays L.) accessions collected in highland areas of
Vietnam revealed by RAPD markers. Journal of Science \& Development 7: 192-202.

Mrutu BA (2015) Assessment of seed genetic purity of hybrid maize variety UH6303 in southern highlands of Tanzania by random amplified polymorphic DNA (RAPD) markers. African Journal of Agricultural Research 10: 2911-2918. doi: 10.5897/AJAR2014.8600.

Mukharib DS, Patil VC, Biradar DP, Salimath PM, Chimmad VP (2010) Assessment of molecular diversity in selected maize inbreds. Karnataka Journal of Agricultural Sciences 23: 409412.

Nei M, Li W (1979) Mathematical model for studying genetic variation in terms of restriction endonucleases. Proceeding of the National Academy of Science of the United State of America 76: 5269-5273.

Shah MM, Hassan SW, Maqbool K, Shahzadi I, Pervez A. (2010) Comparisons of DNA marker-based genetic diversity with phenotypic estimates in maize grown in Pakistan. Genetics and Molecular Research 9: 1936-1945. doi: 10.4238/vol8-3gmr964.

Yadav V, Singh I (2010) Comparative evaluation of maize inbred lines (Zea mays L.) according to dus testing using morphological, physiological and molecular markers. Agricultural Sciences 1: 131-142. doi:10.4236/as.2010.13016. 